\title{
The Pianist: Musical Mobile Application
}

\author{
http://dx.doi.org/10.3991/ijim.v6i4.2093
}

\author{
Abdelrahman Osman Elfaki, Donavan Tan, Suhaila Khalip, \\ Kevin Loo Teow Aik, Sim Liew Fong, Md Gapar Md Johar \\ Management and Science University, Malaysia
}

\begin{abstract}
In this paper, the process of developing a musicalmobile application has been described. The main motivation for this product is to support Samsung BADA apps market. We have developed this product based on two perspectives: educational and entertainment. The product can teach users how to play piano and at the same time, they can use it for fun, i.e., just to play piano like a real piano instrument. Firstly, we have studied and analysed the similar current products to know and understand the main functions of such product. Later we used prototype methodology, the final product generated after 8 prototypes. As a conclusion, this product (The Pianist) introducing a smart phone as a musical instrument which can be used for learning and playing piano.
\end{abstract}

Index Terms-Mobile Application; Muscial Application

\section{INTRODUCTION}

Music is part of our everyday life, in which, playing a music instrument can make people smarter, teaches them discipline, relieves stress, gives a sense of achievement and playing music instruments is fun [1].

On the other hand, smart mobile phones provide the solutions to learn faster compared to traditional learning methods, which is suitable for the impatient type who doesn't like to be at the whim of a teacher. Learning through smart mobile phones will allow the users to follow the pace that the users wishes. If the users pick things up quickly or are eager to learn a particular song, it is possible to put in more efforts and see instant success compared to regular lessons.

Introducing a smart phone as a musical instrument is our contribution in this paper. The musical instrument implemented in this version is a piano. The piano is a music instrument that is beautiful, versatile and can create wonderful music. Playing the piano will also boost the confidence and can also be used as a performance measurement [2].

Learning music is not cheap. The cost includes the physical instrument, the cost of commuting and cost of engaging a music teacher. These costs thwart all those who wish to learn music. In addition to the cost, not everyone can play the physical musical instrument; some might lost their fingers or even an arm but still are music lover and eager to learn musical instrument. Launching a smart phone as a musical instrument provides a good solution to these setbacks.

Developing this application will add new functions for the mobile phones. Smart-phones will be redefined as not only a phone which can make calls and texting; smartphones are now learning tools for music instrument. This application helps to promote piano learning. By trying musical applications in smart-phone, individuals can build interest. Smart-phone as a platform is much easier as it is a piano lesson application on the go. Compared to the traditional approach of learning piano, learning piano using mobile phone is very affordable. Interested users can learn at their own speed which often means learning 10 times faster compared to learning from a standard instructor.

In this product, our contributions are both 1) developing piano-mobile application using Samsung BADA platform. As in market there is no such application for Samsung BADA platform. 2) Adding educational values for the piano-mobile application.

\section{PRELIMINARIES}

In the following are the briefing of some terms related to the proposed product.

Mobile Learning (M-Learning): According to [3], MLearning is the acquisition of any knowledge and skill through using mobile technology, anywhere, anytime that results in an alteration in behaviour. In [4], it is stated that any activity that allows individuals to be more productive when consuming, interacting with, or creating information, mediated through a compact digital portable device that the individual carries on a regular basis, has reliable connectivity and fits in a pocket or purse can also be considered as M-Learning.

Importance of Piano Lessons: It has been proven that learning piano increases eye-hand coordination and is almost a gift for user who can play the piano but there is more than it to that. Those who play the piano have improved fine motor skills and, unlike other instruments, the piano requires both hands to work independently of each other, one moving faster while the other may be moving at a slower rate. All these help to increase the user's overall dexterity and complex thought processes.

Teacher-Student Learning: The learning paradigm, as developed in [5], holds that learning is not merely the acquisition of knowledge by individuals, but instead a process of social participation. The situation where the learning takes place has a great impact on this process. Brown et al. [6], also emphasize the idea of cognitive apprenticeship, where teachers (the experts) work alongside students (the apprentices) to create situations where the students can begin to work on problems even before they fully understand them. Situated learning requires knowledge to be presented in authentic contexts (settings and applications that would normally involve that knowledge) and learners to participate within a community of practice. By developing appropriate context-based teaching strategies with mobile technologies, we can fulfill both of these requirements. 


\section{RELATED PRODUCTS}

In the following, we explained the most downloaded piano mobile applications that are available in the current market.

\section{A. Touch Piano}

This product has been designed for the Iphone. This application only generates sounds when the piano key is touched. There are no instructions on how to use and there are no educational values. In this product, the absence of user's guidance is limited the usability.

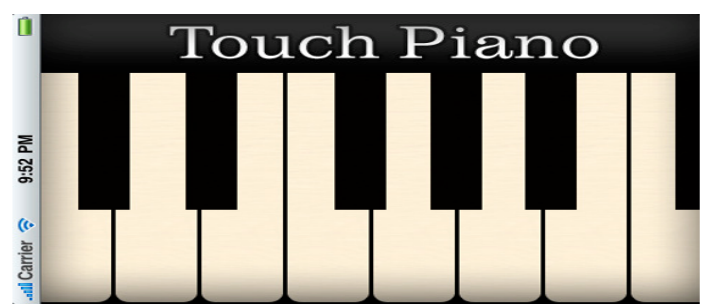

Figure 1. TOUCH PIANO: A musical application for Iphone

\section{B. Virtuoso}

This product has been designed for Iphone, Virtuoso has a scroll bar that consists of 5 octaves and it comes with sound when the key is touched. Even though it consists of 5 full octaves, the screen is small and the scroll bar usage is confusing.

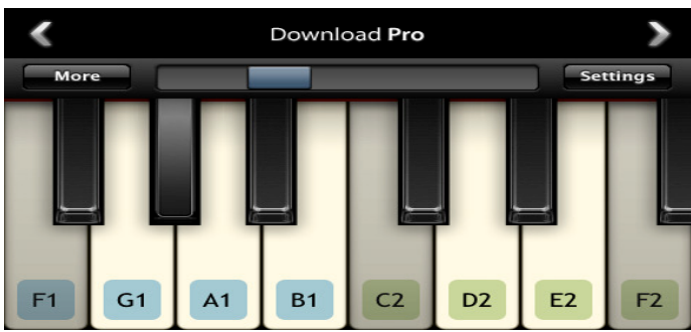

Figure 2. Interface of Virtuoso

\section{Pl Piano Free}

In this product, colour notes will drop down according to the key that need to be pressed. The player feels like he or she is playing the piano but it has only symbols and sound but no piano notes.

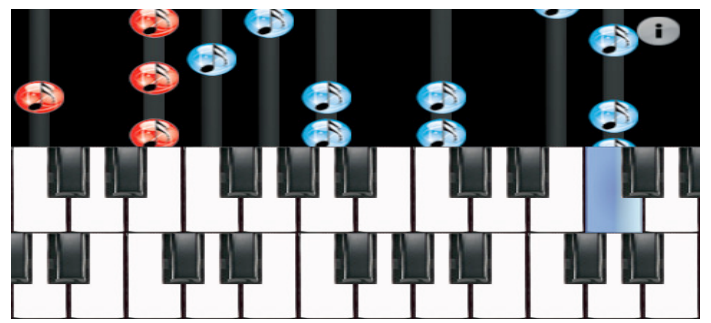

Figure 3. Interface of Pl Piano Free

\section{PianoChords}

In this product, when the key is pressed, it shows the key name and also annotation of shadow of the key pressed. It can accommodate more than 2-3 chords name in the display. However, it doesn't show the notes nor a treble clef in the interface.

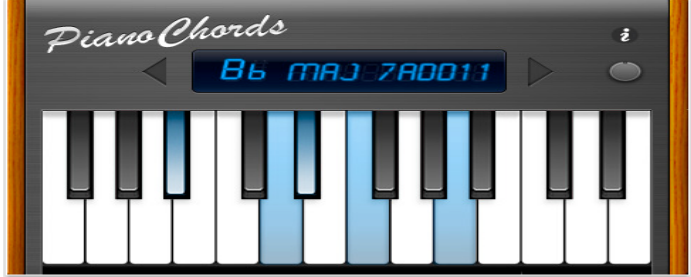

Figure 4. Interface of Piano Chords

\section{E. Pianist}

An Iphone application which contains full 88 keys with zooming function. This application has a built-in metronome to have a good idea of synchronization when using this application. Have multiple functions such as able to pan keyboard, record the key pressed and play after recording.

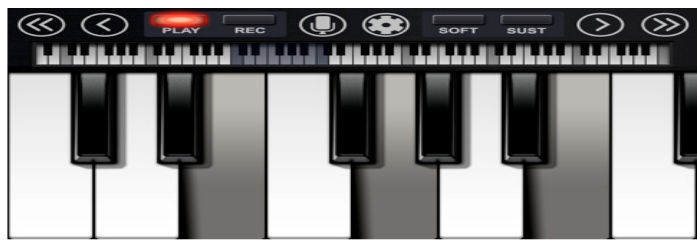

Figure 5. Interface of Pianist

\section{F. Piano Sharp}

Piano sharp is an application which contains five octaves of key with high quality sample piano sound. Able to scroll the piano key with the function of Accelerometer by tilting the mobile phones. Able to play 5 key simultaneously with metronome functions. Demo songs also included.

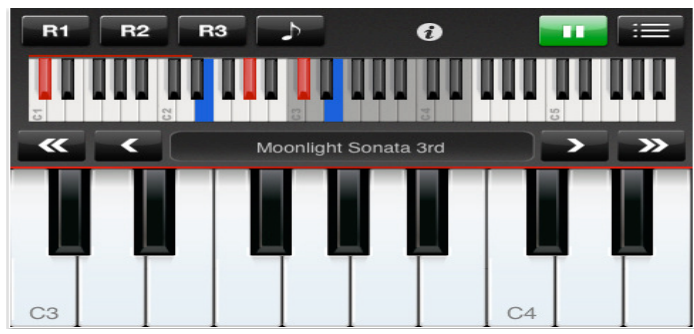

Figure 6. The interface of Piano Sharp.

\section{G. Piano Notes}

Piano Notes contains high quality piano sample with scrollable and playable piano keyboard and also multi-tap playing. This application also has the function of producing a simple statistic of the notes played. It also has the option to set the game play time according to own preferences and with the option to reset the high scores set earlier.

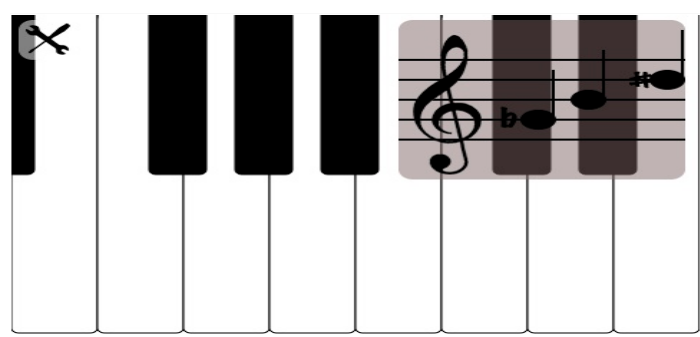

Figure 7. The interface of Piano Notes. 


\section{H. Ikawa Piano}

IkawaPiano is a musical instrument that can be played by allocating a separate tone in an upper and lower keyboard. Ikawa Piano can be converted into various kind of instrument such as electric piano, organ, guitar, bass, strings, and brass, vibraphone, flutes, and synth. On top of that, it contains the piano, and has drum set, drum pattern, harmony, and sound effect.

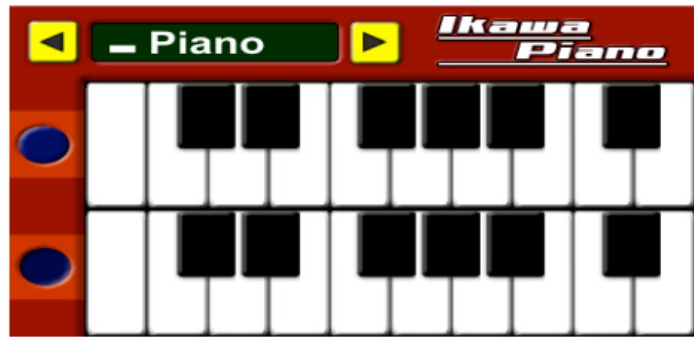

Figure 8. The interface of Ikawa Piano.

\section{Zen Piano}

Zen Piano can record and playback the melody played. It also consists of multiple note support on multitouch with sliding finger note playing. Zen piano also include the technology of TapForce which can sense the pressure that is applied on the surface of the phone.

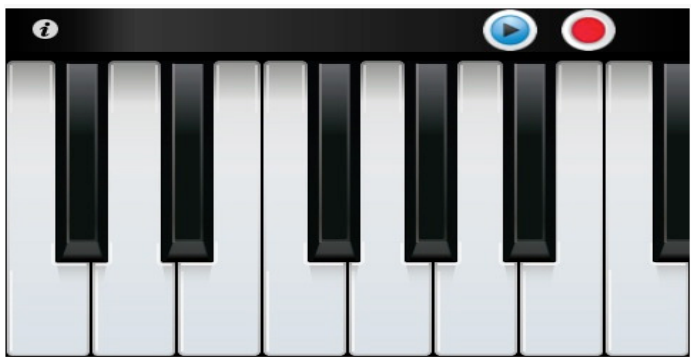

Figure 9. The interface of Zen Piano

\section{J. Amazing Piano}

Amazing Piano is an educational music application, designed to teach users of all ages to learn music and play the piano while having fun without being aware that they are in the "learning" process. Just tap the correct letter in the virtual keyboard to match the note displayed on the screen. It contains functions to guide user how to play piano realistically.

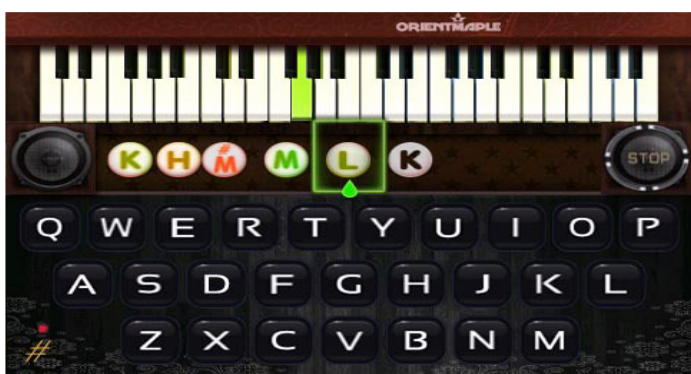

Figure 10. The interface of Amazing Piano

In Table 1, we compared these 10 products in terms of plat form, existence of educational value, and user guidance.
TABLE I.

COMPARISON BETWEEN PIANO MOBILE APPLICATIONS

\begin{tabular}{|c|c|c|c|}
\hline Product & Educational Value & Guidance & Platform \\
\hline $\begin{array}{l}\text { Touch } \\
\text { piano }\end{array}$ & $\begin{array}{l}\text { No educational value as it } \\
\text { only generate sounds }\end{array}$ & No & IOS Only \\
\hline Virtuoso & $\begin{array}{l}\text { No educational value but it } \\
\text { contains full } 5 \text { octaves with } \\
\text { sounds }\end{array}$ & No & IOS Only \\
\hline $\begin{array}{l}\text { Pl piano } \\
\text { free }\end{array}$ & $\begin{array}{l}\text { Partly as it focus on the key } \\
\text { to press according to the } \\
\text { symbols }\end{array}$ & No & IOS Only \\
\hline $\begin{array}{l}\text { Pianochor } \\
\text { ds }\end{array}$ & $\begin{array}{l}\text { Yes as once the key is } \\
\text { pressed, it shows what } \\
\text { chords it is on the screen }\end{array}$ & Yes & $\begin{array}{l}\text { IOS\& } \\
\text { ANDROID }\end{array}$ \\
\hline Pianist & $\begin{array}{l}\text { No, although it contains } 5 \\
\text { full octaves and can record } \\
\text { and replay }\end{array}$ & No & IOS Only \\
\hline $\begin{array}{l}\text { Piano } \\
\text { sharp }\end{array}$ & $\begin{array}{l}\text { Yes, by following the } \\
\text { sample songs which } \\
\text { correspond to the key }\end{array}$ & Yes & IOS Only \\
\hline $\begin{array}{l}\text { Piano } \\
\text { notes }\end{array}$ & $\begin{array}{l}\text { Yes, it shows the notes on } \\
\text { display when the key is } \\
\text { pressed. }\end{array}$ & Yes & $\begin{array}{l}\text { IOS\& } \\
\text { ANDROID }\end{array}$ \\
\hline $\begin{array}{l}\text { Ikawa } \\
\text { piano }\end{array}$ & $\begin{array}{l}\text { No, but it contains upper } \\
\text { and lower keyboard and can } \\
\text { convert into different types } \\
\text { of instruments }\end{array}$ & No & IOS Only \\
\hline Zen piano & $\begin{array}{l}\text { No, only functions is audio } \\
\text { when key pressed, record } \\
\text { and replay. }\end{array}$ & Yes & IOS Only \\
\hline $\begin{array}{l}\text { Amazing } \\
\text { piano }\end{array}$ & $\begin{array}{l}\text { Yes, but by using alphabet } \\
\text { as the corresponding key to } \\
\text { answer. }\end{array}$ & No & IOS Only \\
\hline
\end{tabular}

\section{DeVeloping Methodology}

The prototype methodology has been chosen as a developing methodology for this product. The prototyping methodology is a software development process which allows developers to create portions of the solution to demonstrate functionality and make needed refinements before developing the final solution [7]. We have chosen prototype for the following reasons: - need to get user's feedback to enhance the level of interactivity, get user's suggestions to add new functions, change the necessary changes before final product and testing before release.

Defining the programming language: In this project, we have used Action-Script 2.0 and $\mathrm{C}++$ for the animation. $\mathrm{C}++$ is used in the Samsung Bada Emulator IDE to enable this project to be initiated.

\section{A. Prototypes:}

The first prototype is developed as very simple and basic piano-mobile application. We have analyzed the "Touch piano" product by using reverse-engineering to find the main functions. Then we included these function in our first prototype. After producing the first product we have collected the users' feedback through questionnaire. This process continued until we have developed the final product (prototype number 8 ). Table 2 summarized the prototype development process. 
TABLE II.

SUMMARIZED THE PROTOTYPE DEVELOPMENT PROCESS

\begin{tabular}{|c|c|c|}
\hline $\begin{array}{l}\text { PROTOTYPE } \\
\text { NO } \\
\end{array}$ & BASIC FEATURES & $\begin{array}{l}\text { ADDITIONAL } \\
\text { FEATURES }\end{array}$ \\
\hline 1 & Basic function To Play & - \\
\hline 2 & $\begin{array}{l}\text { Learn to play \& } \\
\text { instruction }\end{array}$ & $\begin{array}{l}\text { Colours for learn } \\
\text { to } \\
\text { instruction }\end{array}$ \\
\hline 3 & $\begin{array}{l}\text { Learn to play \& } \\
\text { instruction }\end{array}$ & $\begin{array}{l}\text { Self-testing } \\
\text { function }\end{array}$ \\
\hline 4 & $\begin{array}{l}\text { Learn to play, } \\
\text { instruction } \& \text { test }\end{array}$ & $\begin{array}{l}\text { Colours for } \\
\text { random test notes } \\
\text { only }\end{array}$ \\
\hline 5 & $\begin{array}{l}\text { Learn to play, } \\
\text { instruction \& test }\end{array}$ & $\begin{array}{l}\text { Colours for } \\
\text { keyboards only }\end{array}$ \\
\hline 6 & $\begin{array}{l}\text { Learn to play, } \\
\text { instruction \& test }\end{array}$ & $\begin{array}{l}\text { Colours for test } \\
\text { function }\end{array}$ \\
\hline 7 & $\begin{array}{l}\text { Learn To Play, } \\
\text { Instruction, Test, Learn } \\
\text { to Play } \\
\end{array}$ & $\begin{array}{l}\text { Play A Song } \\
\text { Function }\end{array}$ \\
\hline 8 & $\begin{array}{l}\text { Learn To Play, } \\
\text { Instruction, Test, Learn } \\
\text { to Play }\end{array}$ & $\begin{array}{l}\text { Colours for Notes } \\
\& \text { Keyboards }\end{array}$ \\
\hline
\end{tabular}

\section{B. Final product (The Pianist)}

We have called the final product "The Pianist". The Pianist has four modules: Learn to Play, Test Yourself, Instruction, and Play a Song. Figure 11 shows the main menu. The Learn to Play module consists of colour annotation, audio and piano notes displayed on the treble clef when the piano key is pressed. The menu button is to go back to the main menu. Figure 12 shows the interface of Learn to Play module. Test Yourself module consists of 2 difficulties which are "Beginner" and "Advance". Figure 13 shows the main menu of test yourself module. Test Yourself-Beginner consists of colour annotation for the piano keys, audios, random generation of note and a score counter. Users need to press the correct notes according to the random notes generated. A score counter will tabulate the correct and incorrect key pressed with percentage of the correct or incorrect key pressed. The "reset" button is to reset the score counter and start over again. Figure 14 explains Test Yourself-Beginner.

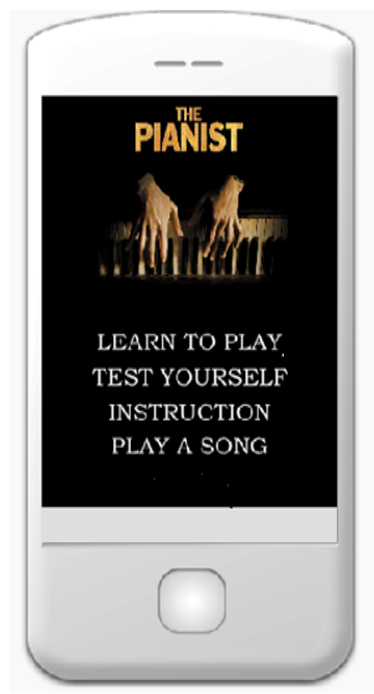

Figure 11. Main Interface of The-Pianist Application
Test Yourself-Advance consists of audios, random generation of notes and a score counter. Users need to press the correct notes according to the random note generated. A score counter will tabulate the correct and incorrect key pressed with percentage of the correct or incorrect key pressed. The "reset" button is to reset the score counter and start over again. Figure 15 explains Test Yourself-Advance.

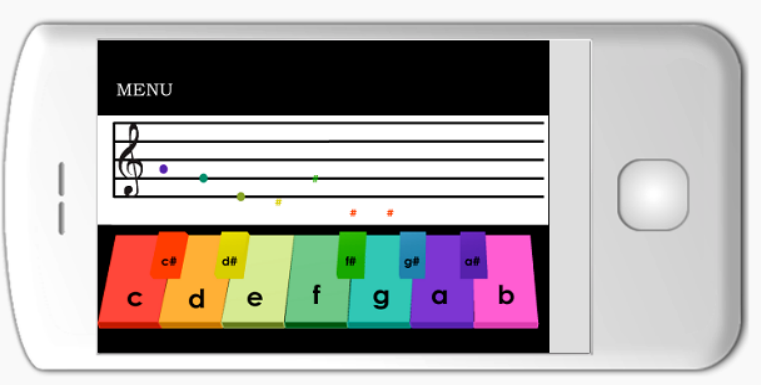

Figure 12. "Learn to Play" Interface

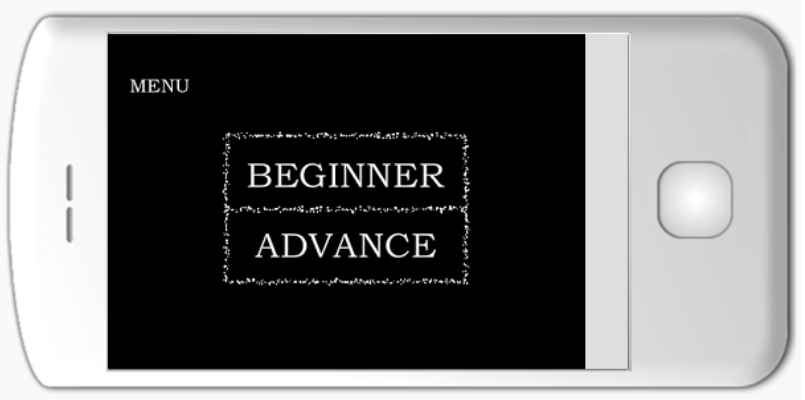

Figure 13. "Test Yourself" Interface

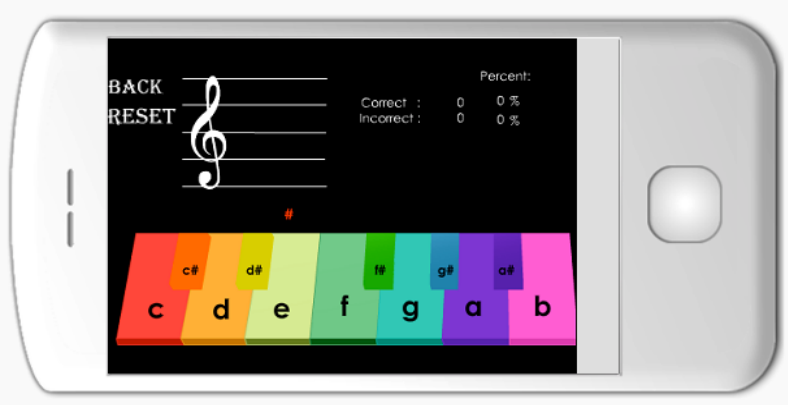

Figure 14. "Test Yourself-Beginner"

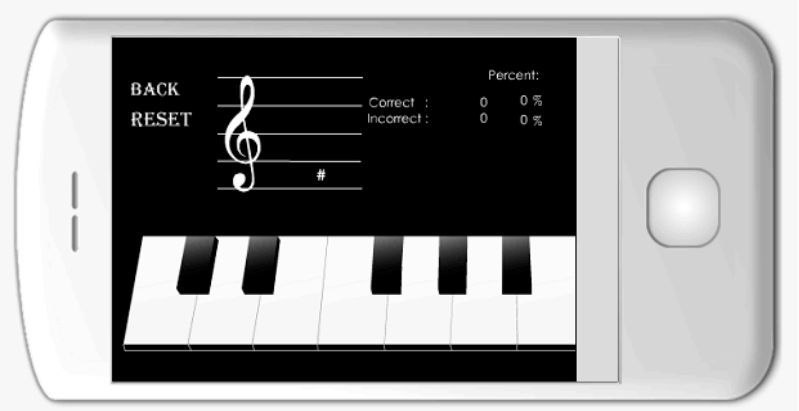

Figure 15. "Test Yourself-Advance" 
TABLE III.

CONTENTS OF THE INSTRUCTION MODULE

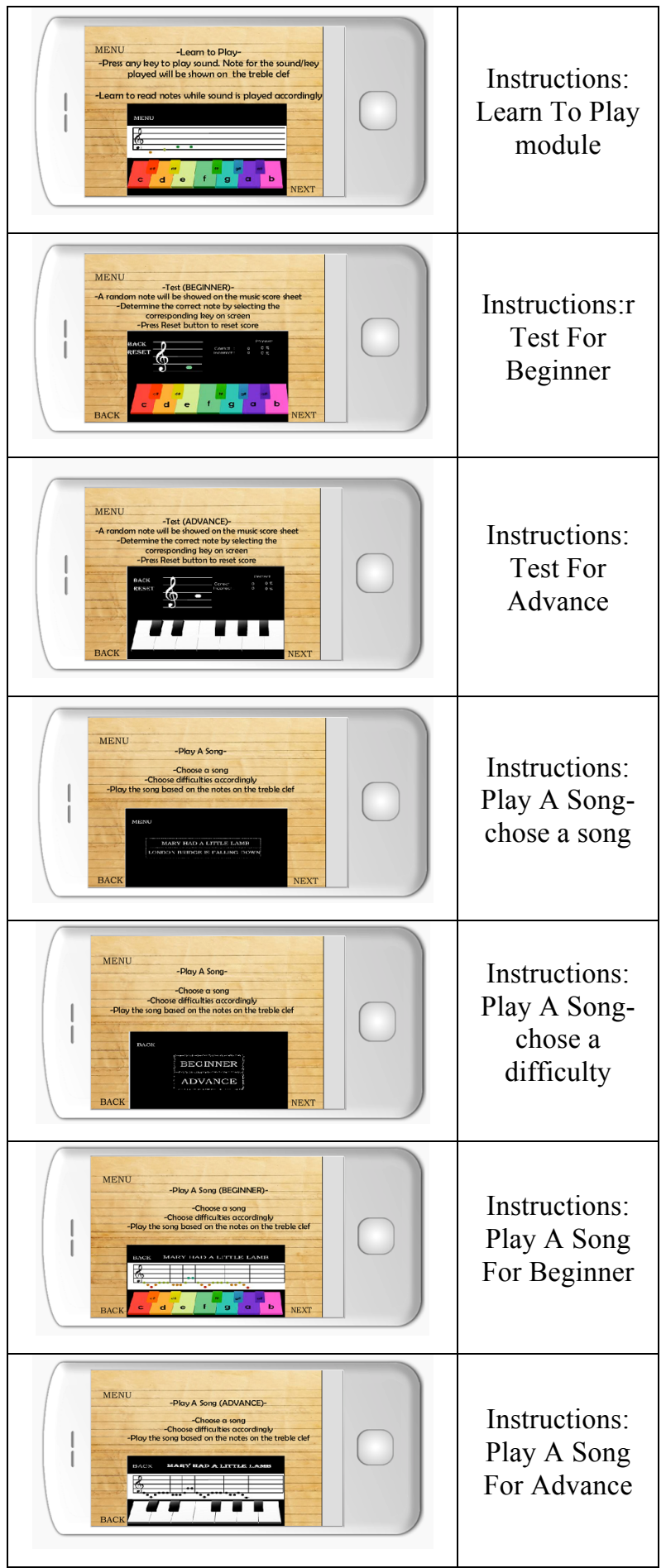

Next module is Instruction. Table III shows the content of Instruction module.

Last module is Play a Song. It consists of two difficulties which is "Beginner" and "Advance". Users can choose either one to play the selected song chosen. Users can play a song based on the notes made available in the treble clef by following them accordingly. This module is supported by colour annotation for the piano key and audio. The beginner level has colouring support where the advance does not have it. Table 3 shows the system flowchart.

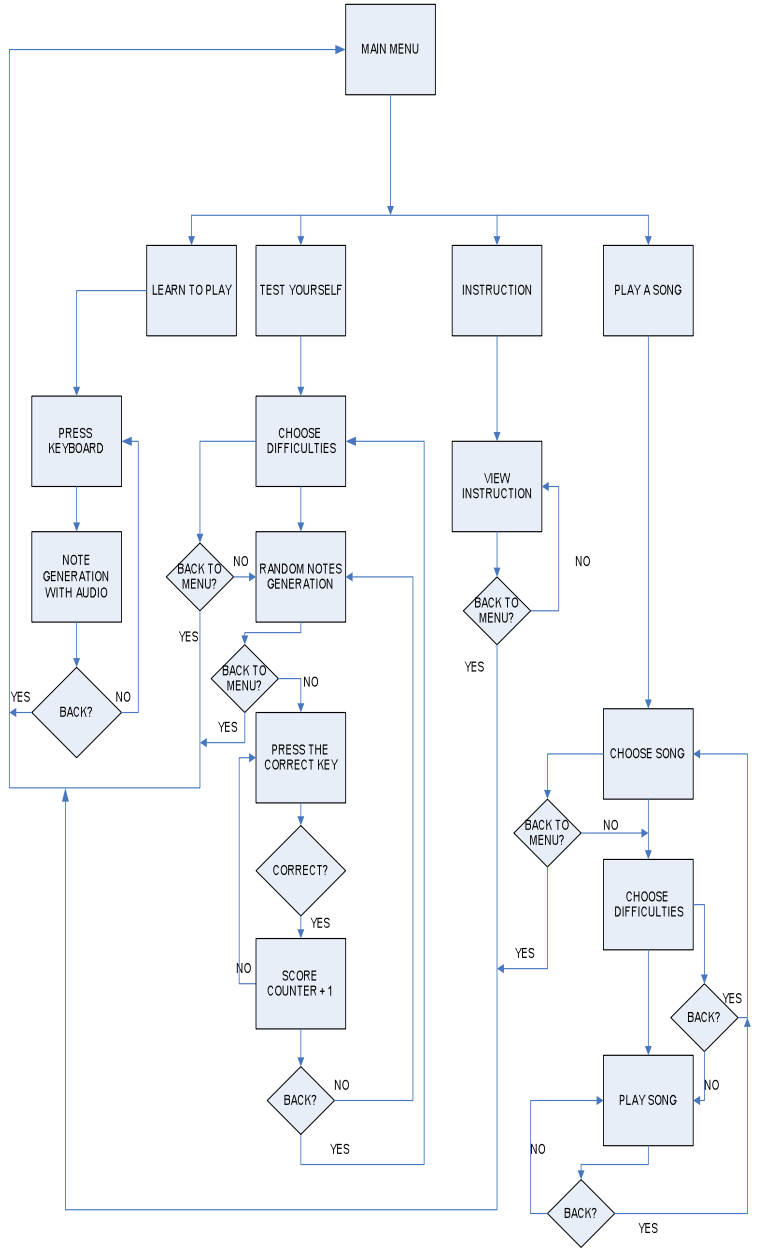

Figure 16. The system flowchart.

Table IV shows the all software used to develop The Pianist.

TABLE IV

THE SOFTWARE USED TO DEVELOP THE PIANIST

\begin{tabular}{|l|l|}
\hline \multicolumn{1}{|c|}{ Software } & \multicolumn{1}{|c|}{ Usage } \\
\hline $\begin{array}{l}\text { Samsung BADA } \\
\text { Emulator SDK }\end{array}$ & $\begin{array}{l}\text { To test out prototype for } \\
\text { Samsung Bada Platform } \\
\text { phones }\end{array}$ \\
\hline $\begin{array}{l}\text { Adobe Central Device } \\
\text { CS5 }\end{array}$ & $\begin{array}{l}\text { To test out the prototypes } \\
\text { for supported mobile } \\
\text { phones }\end{array}$ \\
\hline Adobe Photoshop CS5 & $\begin{array}{l}\text { To edit picture and design } \\
\text { interface. }\end{array}$ \\
\hline Adobe Illustrator CS5 & To edit picture and design. \\
\hline Adobe Flash CS5 & $\begin{array}{l}\text { To design and develop the } \\
\text { said project. }\end{array}$ \\
\hline
\end{tabular}

\section{CONCLUSION}

The Pianist has been developed for all who are interested to learn piano as their hobby and also to substitute the traditional way of learning piano. The Pianist is developed so that users with smart-phones can learn or play piano anytime and anywhere provided that The Pianist has been installed in the desired hardware. The Pianist includes of multimedia elements such as text, graphics, 
animation and audio to visualize and demonstrate the proper usage of piano keys, piano notes, and overall feel of a piano in an interactive way.

As a future work, many more improvements can be added such as save as a ringtone, expansion into full octaves, general tuning of the piano, save the notes played and playback the songs.

\section{REFERENCES}

[1] Emily McGregor, Music Education in Regard to Children, Dissertation submission for CM6002 the Research Module of BA (Hons) in Commercial Music, Bath Spa University, UK, 2011.

[2] Michael T. Kane, Current Concerns in Validity Theory, Journal of Educational Measurement, Winter 2001, Vol. 38, No. 4, pp. 319342 http://dx.doi.org/10.1111/j.1745-3984.2001.tb01130.x

[3] Simon Geddes, Mobile learning in the 21 st century : benefit for learners Abstract MLearning Advantages, Knowledge Creation Diffusion Utilization, Issue: 6, Pages: 1-13, 2004.

[4] Quinn, Clark N. (2011) Designing mLearning: Tapping into the mobile revolution for organizational performance. San Francisco: Pfeiffer. 256 pages. ISBN-13: 978-0470604489.

[5] Laura Naismith, Peter Lonsdale, Giasemi Vavoula, Mike Sharples Literature Review in Mobile Technologies and Learning, technical report, FUTURELAB SERIES, 2004.

[6] Brown, J. S., Collins, A., Duguid, P. . Situated Cognition. Artificial Intelligence and Education, vol.2, pp. 254-268, eds. Robert W. Lawler, Masoud Yazdani, c1987-1991.

[7] Ian Sommerville, Software Engineering, University of St Andrews, Scotland, Addison-Wesley, 2011.

\section{AUTHORS}

Donavan Tan is with Faculty of Information Sciences and Engineering, Management and Science University, Malaysia,dont320@gmail.com

Suhaila Khalip is with Faculty of Information Sciences and Engineering, Management and Science University, Malaysia, suhaila@msu.edu.my

Sim Liew Fong is with Faculty of Information Sciences and Engineering, Management and Science University, Malaysia, lfsim@msu.edu.my

Abdelrahman Osman Elfaki is with Faculty of Information Sciences and Engineering, Management and Science University, Malaysia, abdelrahmanelfaki@gmail.com

Kevin Loo Teow Aik is with Faculty of Information Sciences and Engineering, Management and Science University, Malaysia, kevin@msu.edu.my

Md Gapar Md Johar is with Faculty of Information Sciences and Engineering, Management and Science University, Malaysia,gapar@msu.edu.my

Received 15 April 2012. Published as resubmitted by the authors 23 September 2012. 